\title{
How the Export Volume Is Affected by Determinant Factors in a Developing Country?
}

\author{
Ashkan Ebadi ${ }^{1} \&$ Azadeh Ebadi $^{2}$ \\ ${ }^{1}$ Concordia Institute for Information Systems Engineering, Concordia University, Montréal, Canada \\ ${ }^{2}$ Faculty of Economics, Allameh Tabatabai University, Tehran, Iran \\ Correspondence: Ashkan Ebadi, Postdoctoral Researcher, Concordia University, Montréal, QC H3G 1M8, Canada. \\ Tel: 1-514-848-2424 \#5069. E-mail: a_ebad@encs.concordia.ca
}

\author{
Received: January 12, 2015 \\ Accepted: February 4, 2015 \\ Online Published: February 6, 2015 \\ doi:10.5430/rwe.v6n1p143 \\ URL: http://dx.doi.org/10.5430/rwe.v6n1p143
}

\begin{abstract}
The export volume can be regarded as one of the important macroeconomic measures of a country development. Although the international trade volume has been increased significantly during the past years, the share of developing countries is still not comparable with the developed ones. This paper analyzes the inter-relations among export and some quantitative and qualitative measures in a developing country, i.e. Iran. The focus is more on the exchange rate volatility. For this purpose, multiple regression analysis was preformed over the period of 1961 to 2001. Our results confirm the important role of pricing and non-pricing variables in stimulating the export of the examined country. Moreover, a negative impact of the external shocks was observed especially for the industrial goods export.
\end{abstract}

Keywords: export, exchange rate, inflation rate, developing country, econometrics

\section{Introduction}

In recent times, the international trade volume has significantly increased and different countries are competing to not only maintain their international trade level but augment their share. However, the trade volume of the developing countries seems to be more vulnerable against the internal and external shocks. One of the most important factors in this regard is the exchange rate volatility for which its consequences on trade have long been at the centre of the debate on optimality of alternative exchange rate regimes. After the termination of the Bretton Woods system in 1971, the world economy shifted from fixed exchange rate to flexible exchange rate regime (Bordo, 1993). The high degree of volatility and uncertainty of exchange rate since the advent of the flexible system in 1973 encouraged researchers to investigate the nature and extent of the impact of such changes on the trade volume. The increasing volatility of exchange rates has been a constant source of concern for both policymakers and academics. Developed countries fought hard in the 1980s to limit US dollar fluctuations (e.g. Plaza Accord and Louvre agreement, respectively in 1985 and 1987), and some European countries took an even more radical decision by giving up their national currency for Euro in 1999.

It is assumed that exchange rate risk increases the transaction costs thus reduces the gains to international trade. However, studies that evaluated the impact of exchange rate uncertainty on trade especially after the breakdown of the Bretton Woods system have reached to mixed results. It is mainly argued in the literature that the exchange rate volatility (Note 1) can negatively affect the risk averse exporters/firms (e.g. Ethier, 1973; Peree \& Steinherr, 1989). However, some other studies suggest a positive impact of exchange rate volatility on the trade flows (e.g. Franke, 1991; Sercu \& Vanhulle, 1992). Interestingly, there are also some studies that stay in the middle and propose an ambiguous impact of the exchange rate volatility on trade (e.g. Viaene \& De Vries, 1992; Barkoulas et al., 2002) due to several reasons such as type of shocks on exporters.

Moreover, the inconsistency of results of the empirical studies has made it very difficult to have a clear conclusion. Although several empirical studies showed a negative impact of exchange rate movements on trade (e.g. Cushman, 1983; Kenen \& Rodrik, 1986; Thursby \& Thursby, 1987), other studies found insignificant effects (e.g. Gagnon, 1993) or even a slightly positive impact of the exchange rate uncertainty (e.g. Bauem et al., 2004; Baum \& Caglayan, 2010). More interestingly, there exist some studies that found both negative and positive impact of exchange rate uncertainty on trade (e.g. Klein, 1990; Kroner \& Lastrapes, 1993). 
Most of the studies above focused on the developed countries. In addition, a limited number of studies considered the possibility of a different impact of the mentioned factors in countries with different levels of development (e.g. Arize et al., 2000; Sauer \& Bohara, 2001; Caglayan \& Di, 2010). Recently, researchers focused on developing countries and assessed the impact of exchange rate volatility. Arize et al. (2000) examined the impact of exchange rate volatility in 13 developing countries and found a significant negative effect. In another study, Sauer and Bohara (2001) focused on 22 developed and 69 developing countries and found a negative impact of exchange rate volatility on the aggregate exports of the examined developing countries. Grier and Smallwood (2007) examined the impact of exchange rate volatility on the aggregate export of nine developed as well as nine developing countries. Their results suggest a negative effect of exchange rate uncertainty in developing countries. However, in two other studies, i.e. Baum and Caglayan (2010) and Caglayan and $\mathrm{Di}$ (2010), researchers used aggregate and bilateral sectoral exports respectively to evaluate and compare the effect in the selected developed and developing countries and found an insignificant or negligible relation.

Hence, as it can be seen no general consensus is found in the literature about the impact of exchange rate uncertainty on the export volume. One reason could be the use of different target countries and as a result different datasets for the purpose of the study. In addition, the focus of researchers has been mostly on the developed countries rather than developing ones. This calls for a more comprehensive and integrated study to be performed in developing countries. Using large-scale data, this paper is designed to comprehensively assess the impact of exchange rate volatility as well as other selected influencing factors on the export volume of a developing country. The focus is on the export of Iran as a developing country in the Middle East region within the period of 1961 to 2001. The rest of the paper is organized as follows: Section "Data and Methodology" describes methodology and data used in this study. The empirical results and interpretations are provided in section "Results". Section "Conclusion" presents the findings and the limitations of this study are discussed in the last section titled "Limitations".

\section{Data and Model Specification}

\subsection{Data}

Iran was selected as the target country in this study. The strategic role of the country in the Middle East region, the existence of severe exchange rate movements and the external shocks (e.g. embargo, war) that have been applied over the years were some of the reasons that encouraged us to evaluate the relation between exchange rate uncertainty and exports in the mentioned developing country. The panel data within the period of 1961 to 2001 was used for evaluating the impact on the total and non oil exports of the country while another dataset from 1972 to 2001 was employed for assessing the impact of uncertainty on the industrial goods export. The required data was first collected from various sources (i.e. Statistical Centre of Iran (Note 2), Central Bank of Iran (Note 3), National Organization of Planning and Management (Note 4) and Customs Organization of Iran (Note 5)) and then integrated into a single dataset.

\subsection{Model Specification and Variables}

Studies performed in the developed countries mostly suggest that export can be a function of the price variables such as exchange rate, inflation and external income. These countries possess a well-established production structure and powerful economy that make the mentioned variables good descriptors of the export function. However, this is not the case in the developing countries whose production structures are not so powerful. Hence, it seems that some other variables that might have an effect on reducing prices (e.g. productivity) can be also included in the equations. Moreover, in macroeconomic and public sector analyses export is mostly considered as a function of exchange rate, internal prices and external income. But in developing countries non-price variables should be also included. In Iran, the external incomes do not play an important role since goods competitiveness is not mainly considered as an important factor for export and the export volume (especially non oil products) is not so high comparing to the world level. In addition, inflation looks to be a more important player for the examined country rather than the general price level. High inflation rates definitely harm the investment decisions that might affect the export volume. As a representative for the external shocks, a dummy variable of war was also included in the model as a negative impact on export was expected during the Iran-Iraq war (Note 6). Hence, in this paper the generic form of the export function is defined as follows:

$$
\operatorname{Exp}_{i}=f(E R, I R, P R, C M, W)
$$

where Exp is the total export volume in million dollars, $E R$ is the free market exchange rate, $I R$ represents the inflation rate, $P R$ is the work force productivity variable, $C M$ is the competitiveness factor and $W$ represents the war effect. For calculating the productivity $(P R)$ the common approach was considered in which productivity is defined 
as the ratio of the gross national product (GNP) to the working population in the labor market (Note 7). As a proxy of the competitiveness $(C M)$, the ratio of the Iranian export to the world export volume was calculated and considered. This was based on the assumption that the more competitive a country is in the international markets the more demand would be for its products (Note 8). For estimating the relationships among the variables, multiple regression analysis was used. In particular, three dependent variables, i.e. total export $\left(\operatorname{Tot}_{\operatorname{Exp}}\right)_{i}$, the ratio of non oil export to the total export (NonOilExp $\left.{ }_{i}\right)$, and industrial goods export $\left(\operatorname{IndExp}_{i}\right)$ were estimated each based on a specific version of equation (1) that will be explained in their respective parts in Section 3. STATA 12 (Note 9) data analysis and statistical software was used to estimate the models.

\section{Results}

In this section, the trends of exchange rate and export volume are first analyzed and then the results of the statistical analyses are presented and discussed.

\subsection{Descriptive Analysis}

As it can be seen in Figure 1-a, the overall trend of the exchange rate is increasing over the examined time interval where a drastic increase is observed especially after 1992. According to the results, the examined time interval can be divided into four different periods based on the trends of the exchanges rate movements and export volume (Note 10). From 1961 to 1973 (Period I) a slight and continuous decrease in exchange rate is observed (Figure 1-b). Although the liquidity growth rate was significant in this period, due to the high growth of the gross national product and lack of inflation expectation a relatively low inflation rate is observed (between 0.1 and 5.6). Comparing Figures $1-b$ and 2-b, although a slight decrease in exchange rate is observed the export volume has raised rapidly in Period I. Of course these results do not reflect causality between the mentioned factors. However, it seems that low inflation rate, price stability, high liquidity and high growth rate of GNP were some of the most important factors in encouraging the export of the examined country.
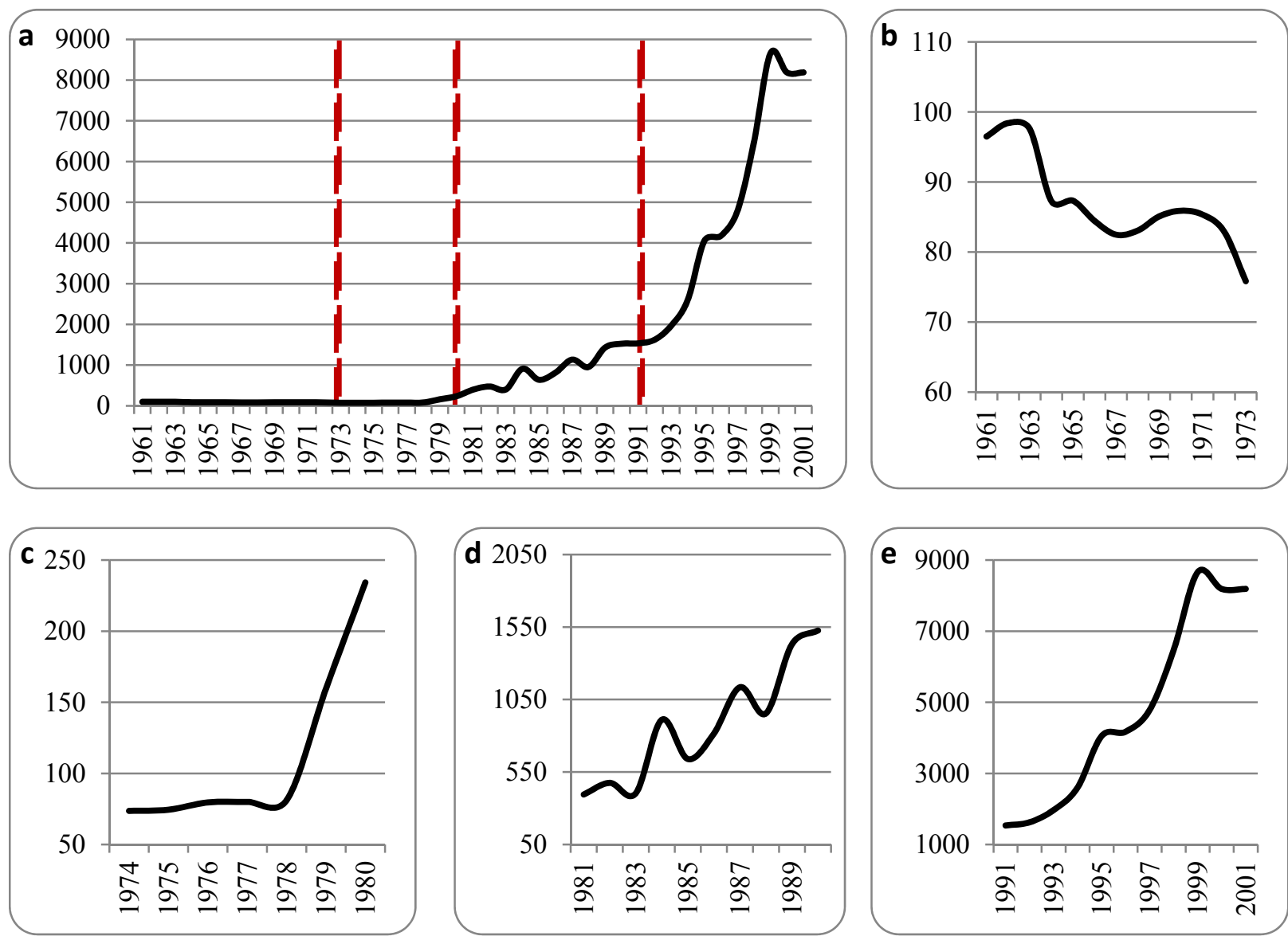

Figure 1. a) Overall exchange rate trend, b) Exchange rate trend in Period I, c) Exchange rate trend in Period II, d) Exchange rate trend in Period III, and e) Exchange rate trend in Period IV 
From 1974 to 1980 (Period II) country experienced a very high growth of liquidity mainly due to the drastic increase of the oil price. As it can be seen in Figure 1-c, exchange rate started to increase rapidly after the Islamic revolution in 1979. Although the growth rate of GNP was first positive, it became negative after 1977. After 1979 a growth in the export is expected as the exchange rate has risen rapidly. But, relatively high inflation rates especially after the revolution (1979) seems to be an influencing factor that caused a drastic decline in the export volume (Figure 2-c). Another reason might be the high oil incomes of the country within the Period II that not only resulted in higher export but also due to the Dutch disease (Note 11) harmed the export volume.
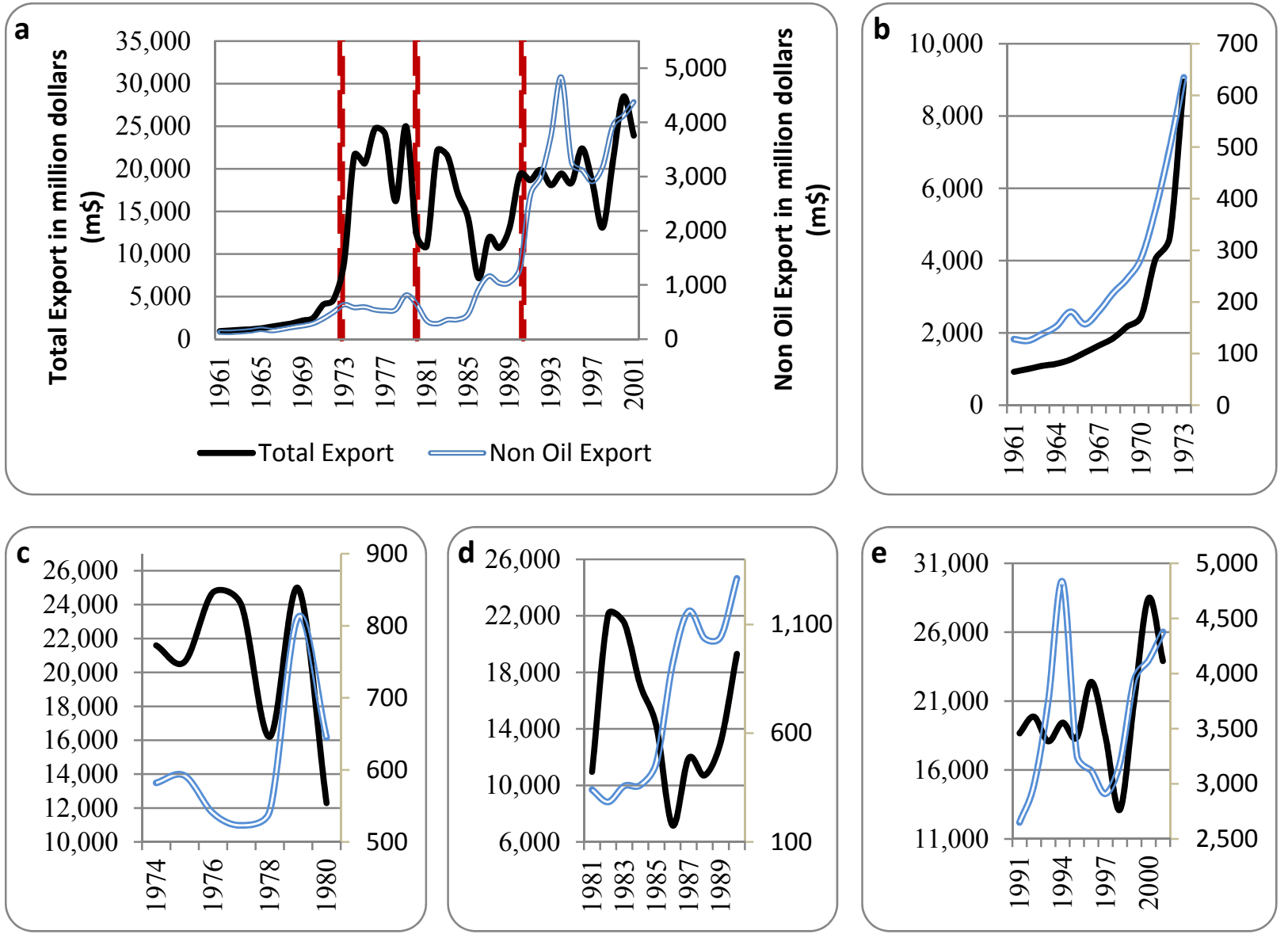

Figure 2. a) Total export and non oil export trends, b) Total export and non oil export trends in Period I, c) Total export and non oil export trends in Period II, d) Total export and non oil export trends in Period III, and e) Total export and non oil export trends in Period IV

The third period spans from 1981 to 1990 (Period III) in which the Iran-Iraq war happened. Economic and political difficulties (especially during the beginning years of the war) are the specific feature of this period. An almost constant increase of the exchange rate is observed in Period III (Figure 1-d). Comparing Figures 1-d and 2-d, it can be seen that trends of the exchange rate and non oil export are almost similar. However, this is not the case for the total export as some severe fluctuations are observed within Period III. Another interesting point is the constant or slightly increasing trend of the non oil export of the examined country within the first three periods (i.e. Period I, II and III). This can partially confirm the important role of other influencing factors rather than the exchange rate in stimulating the export volume of a country. The last period spans from 1991 to 2001 in which the structural adjustment programs occurred in the examined country. Economic adjustment programs focused on the increase of the industrial exports. In addition, the exchange rate policies of the country targeted better allocation of the resources in order to increase the non-oil exports. However, according to Figure 1-e the exchange rate has increased drastically during Period IV. In addition, as it can be seen in Figure 2-e although the export (especially non oil export) has raised within this period the overall increase is not very significant in a way that the export volume has fluctuated within an almost small range. 


\subsection{Statistical Analysis}

In this section the estimation results of the export models are presented and discussed. As mentioned before, export was modeled as a function of price variables (e.g. exchange rate and inflation) as well as qualitative variables (e.g. productivity and competitiveness).

\subsubsection{The Total Export}

To evaluate the impact of the influencing factors on the volume of the total export, correlation among the variables was first tested. In addition, various lags of the variables were tested where it was found that a 1-year lag for the competitiveness independent variable produces the most significant result. Hence, based on the correlations the following model was used to analyze the total export:

$$
\operatorname{TotExp}_{i}=\beta_{0}+\beta_{1} E R_{i}+\beta_{2} I R_{i}+\beta_{3} C M_{i-1}+\beta_{4} W_{i}+\varepsilon_{i}
$$

The definition of the independent variables are the same as the ones that were defined for the generic form of the export model in equation (1), except the one year lag that was considered here for the competitiveness variable. The dummy variable $W_{i}$ represents the existence of war in the given year $i$. The results of the multiple regression analysis are shown in Table 1. As it can be seen, the exchange rate has a positive relation with the total export volume. This is quite expected as higher exchange rate itself can make the products cheaper for the foreign buyers that will result in higher export volume. However, the results suggest a higher positive impact of the inflation rate on the export volume. Due to the high inflation rates in the examined country it seems that the inflation movements have neutralized the potential positive impact of the exchange rate on the export volume.

Table 1. Regression result, total export model

\begin{tabular}{|c|c|c|c|c|c|c|}
\hline $\operatorname{Tot}_{\operatorname{Exp}}$ & Coef. & Std. Err. & $t$ & $P>|t|$ & \multicolumn{2}{|c|}{ [95\% Conf. Interval] } \\
\hline$e r_{i}$ & $1.940498^{* * *}$ & .4109683 & 4.72 & 0.000 & 1.106188 & 2.774808 \\
\hline$i r_{i}$ & $269.8471^{* * *}$ & 88.87511 & 3.04 & 0.005 & 89.42099 & 450.2731 \\
\hline$c m_{i-1}$ & $8679.241^{* * *}$ & 1673.071 & 5.19 & 0.000 & 5282.727 & 12075.75 \\
\hline \multicolumn{7}{|c|}{ War dummy variable } \\
\hline$W_{i}$ & 882.8907 & 2184.497 & 0.40 & 0.689 & -3551.874 & 5317.655 \\
\hline cons & 932.1262 & 1837.523 & 0.51 & 0.615 & -2798.243 & 4662.495 \\
\hline
\end{tabular}

Notes: ${ }^{*} \mathrm{p}<0.10,{ }^{* *} \mathrm{p}<0.05,{ }^{* * *} \mathrm{p}<0.01$, number of observations: 40

Since the competitiveness variable has a significant positive relation with the export volume and considering the one year lag, based on the definition of the mentioned variable the results partially confirm the importance of the export volume in the previous years as well as the position of the country in the world market in achieving higher export in the coming years. According to the results the war dummy variable does not have a significant impact on the total export volume.

\subsubsection{The Non Oil to the Total Export}

The same analysis as described in the previous section was performed for the non oil export volume of the examined country. According to the preliminary tests, the same model as the equation (2) appeared to be best model producing the most robust results. As discussed earlier in section 2.2 the dependent variable (NonOilExp $\left.)_{i}\right)$ is the ratio of the non oil export to the total export in year $i$. The estimation results are shown in Table 2. According to the results the exchange rate and inflation rate have positive impact on the non oil export. In addition, the inflation rate has larger coefficient than the exchange rate which is the same as the results for the total export model (Table 1). Hence, the previous discussions about the effect of exchange rate and inflation rate are also valid for the non oil export model. However, interestingly the competitiveness is showing a significant negative effect on the non oil export. Since the competitiveness variable is calculated based on the share of the total export of the country to the world amount, this result partially confirms the negative impact of the high total export in the previous year on the non oil export in the coming year. In other words, since the economy of the examined country is highly dependent on oil (or oil related products) it seems that if the export largely concentrates on the oil products it may harm the export of the non oil 
goods. Moreover, the results suggest a negative impact of war on the non oil exports. Hence, although according to Figure 2-d the non oil export has followed a relatively increasing trend within the Period III, it was affected negatively by the Iran-Iraq war in a way that if the war did not happen, a more drastic increasing trend could be expected.

Table 2. Regression result, non oil to the total export model

\begin{tabular}{|c|c|c|c|c|c|c|}
\hline NonOilExp $_{i}$ & Coef. & Std. Err. & $t$ & $P>|t|$ & \multicolumn{2}{|c|}{ [95\% Conf. Interval] } \\
\hline$e r_{i}$ & $7.17 \mathrm{e}-06^{* *}$ & $2.82 \mathrm{e}-06$ & 2.54 & 0.016 & $1.44 \mathrm{e}-06$ & .0000129 \\
\hline$i r_{i}$ & $.0014061^{* *}$ & .0006104 & 2.30 & 0.027 & .0001669 & .0026454 \\
\hline$c m_{i-1}$ & $-.0598274^{* * *}$ & .0114914 & -5.21 & 0.000 & -.0831562 & -.0364986 \\
\hline \multicolumn{7}{|c|}{ War dummy variable } \\
\hline$W_{i}$ & $-.0623319^{* * *}$ & .0150041 & -4.15 & 0.000 & -.0927919 & -.0318719 \\
\hline cons & $.1239393^{* * *}$ & .0126209 & 9.82 & 0.000 & .0983174 & .1495612 \\
\hline
\end{tabular}

Notes: ${ }^{*} \mathrm{p}<0.10,{ }^{* *} \mathrm{p}<0.05,{ }^{* * *} \mathrm{p}<0.01$, number of observations: 40

3.2.3 The Industrial Goods Export

In the last part of the statistical analysis, we focused on the industrial goods export volume. For modeling the industrial goods export, two quantitative variables (i.e. exchange rate and inflation rate) as well as a qualitative measure of productivity (defined in section 2.2) and the dummy variable of war were used (equation 3). Due to the lack of data the relations were analyzed for the period of 1972 to 2001.

$$
\operatorname{IndExp}_{i}=\beta_{0}+\beta_{1} E R_{i}+\beta_{2} I R_{i}+\beta_{3} P R_{i}+\beta_{4} W_{i}+\varepsilon_{i}
$$

The estimation results are shown in Table 3 . The same as the previous estimations, the results suggest a significant positive impact of exchange rate and inflation on the export of industrial goods. Since the industrial goods export of the examined country is negligible, the same direction of exchange rate and inflation rate coefficients along with the larger effect that is observed for the inflation rate is partially confirming the neutralizing role of the high inflation rates. In other words, if the inflation movements are controlled then higher exchange rates can show more positive impact on the industrial goods export. Surprisingly, the productivity measure does not show a significant impact. As expected, the war has a large significant negative impact on the export of industrial goods.

Table 3. Regression result, industrial goods export model

\begin{tabular}{lcrrrrr}
\hline IndExp & \multicolumn{1}{c}{ Coef. } & Std. Err. & \multicolumn{1}{c}{$\boldsymbol{t}$} & \multicolumn{1}{c}{$\boldsymbol{P}>|\boldsymbol{t}|$} & \multicolumn{2}{c}{ [95\% Conf. Interval] } \\
\hline er $_{i}$ & $.2472833^{* * *}$ & .0191379 & 12.92 & 0.000 & .2078681 & .2866985 \\
$i r_{i}$ & $10.61748^{*}$ & 5.2139 & 2.04 & 0.052 & -.120744 & 21.35571 \\
$p r_{i}$ & 2.542352 & 20.4788 & .12 & 0.902 & -39.63453 & 44.71924 \\
& & & & & & \\
\hline War dummy variable & & & & & & \\
$W_{i}$ & $-309.3494^{* *}$ & 121.4968 & -2.55 & 0.017 & -559.5766 & -59.12214 \\
& & & & & & \\
\hline cons & -38.36004 & 485.8704 & -0.08 & 0.938 & -1039.029 & 962.3088
\end{tabular}

Notes: ${ }^{*} \mathrm{p}<0.10,{ }^{* *} \mathrm{p}<0.05,{ }^{* * *} \mathrm{p}<0.01$, number of observations: 30

\section{Discussion}

Exchange rate is one of the most determinant macroeconomic variables that can influence other economic variables such as production, export, balance of payments, etc. In the examined country, the government has the exclusive right of foreign currency pricing. High exchange rate volatilities can cause severe inflations which might 
significantly harm a developing economy (e.g. changes in the structure of production and investment, changes in the domestic and foreign markets). The intensive oil and gas reservoirs of the country have made the economy highly dependent on the export of oil products, hence, making it vulnerable against severe external shocks (e.g. change in oil price). Export volume is one of the determinant factors in determining the growth and development of an economy. After 1970s, export development played an important role in the economic growth of several developing countries, e.g. newly industrialized countries of Southeast Asia. The adherents of the export development strategy believe that such strategy can cause an increase in production hence reducing the unemployment rate. In addition, it can adjust the balance of payments through attracting foreign investment and income.

This paper used a large range of panel data to investigate the relation between some influencing factors and the export volume in a developing country, namely Iran. For this purpose, a number of quantitative and qualitative measures were used where the results confirmed the important role of price variables (e.g. exchange rate) as well as non-price variables (e.g. competitiveness) in describing the export volume. Hence, it is not wise to just focus on the price variables in order to stimulate the export of a developing country in the long run. Moreover, the supply side needs and satisfying the structural and qualitative requirements look necessary for accelerating the export. In addition, the negative effect of the external shocks on the industrial exports is inevitable as it was observed for the Iran-Iraq war. Hence, a safer and more stable environment can also provide a better situation for the development of an economy.

According to the results, although the total and non oil exports of the examined country have experienced several up and downs especially within the last period of the study (1991-2001), an increase in the volume of the non-oil export is observed which might be mainly due to the exchange rate policies of the country within the mentioned period (since a drastic raise is seen in the amount of the exchange rate within the same period). In addition, although the limitation and control of the inflation rate is needed for increasing the higher effectiveness of the exchange rate policies, it does not look sufficient. In other words, removing the obstacles of investment also looks necessary in order to increase the competition among the internal producers. This will also help the local producers to increase their products' quality by getting familiar with foreign know-how and standards. Considering the mortality of the fossil fuels it seems mandatory for the examined economy to focus more on the non oil products. The relatively low volume of the non oil exports within the whole examined time interval partially confirms this proposition.

Last but not least, while our analysis sheds light on the inter-relations among some important influencing factors and the export volume in a developing country, one may notice that these relations are time based and country specific. That means not only the effects would differ in the same country in different times but also other developing countries may experience different impacts based on their internal economic structures, policies, domestic factors, etc. However, despite the differences it can be said that the exchange rate stability as well as stable economic environment can be definitely helpful in promoting a country's export. Future research would examine other developing countries (at different levels of development) to compare the results.

\section{Limitations}

The main limitation of this paper was in regards to the collecting of the required data. We focused on the time interval of 1961 to 2001 for the total and non oil exports while used the period of 1972 to 2001 for the industrial goods export. Using larger datasets not only can be helpful in confirming the results but also can make it possible to include more variables for the analysis.

\section{References}

Arize, A. C., Osang, T., \& Slottje, D. J. (2000). Exchange-rate volatility and foreign trade: Evidence from thirteen LDC's. Journal of Business \& Economic Statistics, 18(1), 10-17. http://dx.doi.org/10.2307/1392132

Barkoulas, J. T., Baum, C. F., \& Caglayan, M. (2002). Exchange rate effects on the volume and variability of trade flows. Journal of International Money and Finance, 21(4), 481-496. http://dx.doi.org/10.1016/S0261-5606(02)00003-7

Baum, C. F., \& Caglayan, M. (2010). On the sensitivity of the volume and volatility of bilateral trade flows to exchange rate uncertainty. Journal of International Money and Finance, 29(1), 79-93. http://dx.doi.org/10.1016/j.jimonfin.2008.12.003

Baum, C. F., Caglayan, M., \& Ozkan, N. (2004). Nonlinear effects of exchange rate volatility on the volume of bilateral exports. Journal of Applied Econometrics, 19(1), 1-23. http://dx.doi.org/10.1002/jae.725

Bollerslev, T. (1986). Generalized autoregressive conditional heteroskedasticity. Journal of Econometrics, 31(3), 307-327. http://dx.doi.org/10.1016/0304-4076(86)90063-1 
Bordo, M. D. (1993). The bretton woods international monetary system: A historical overview. A retrospective on the bretton woods system: Lessons for international monetary reform (pp. 3-108) University of Chicago Press. http://dx.doi.org/10.7208/chicago/9780226066905.001.0001

Caglayan, M., \& Di, J. (2010). Does real exchange rate volatility affect sectoral trade flows? Southern Economic Journal, 77(2), 313-335. http://dx.doi.org/10.4284/sej.2010.77.2.313

Cushman, D. O. (1983). The effects of real exchange rate risk on international trade. Journal of International Economics, 15(1), 45-63. http://dx.doi.org/10.1016/0022-1996(83)90041-7

Ethier, W. (1973). International trade and the forward exchange market. The American Economic Review, 494-503.

Franke, G. (1991). Exchange rate volatility and international trading strategy. Journal of International Money and Finance, 10(2), 292-307. http://dx.doi.org/10.1016/0261-5606(91)90041-H

Gagnon, J. E. (1993). Exchange rate variability and the level of international trade. Journal of International Economics, 34(3), 269-287. http://dx.doi.org/10.1016/0022-1996(93)90050-8

Grier, K. B., \& Smallwood, A. D. (2007). Uncertainty and export performance: Evidence from 18 countries. Journal of Money, Credit and Banking, 39(4), 965-979. http://dx.doi.org/10.1111/j.1538-4616.2007.00053.x

Kenen, P. B., \& Rodrik, D. (1986). Measuring and analyzing the effects of short-term volatility in real exchange rates. The Review of Economics and Statistics, 311-315. http://dx.doi.org/10.2307/1925511

Klein, M. W. (1990). Sectoral effects of exchange rate volatility on United States exports. Journal of International Money and Finance, 9(3), 299-308. http://dx.doi.org/10.1016/0261-5606(90)90011-N

Kroner, K. F., \& Lastrapes, W. D. (1993). The impact of exchange rate volatility on international trade: Reduced form estimates using the GARCH-in-mean model. Journal of International Money and Finance, 12(3), 298-318. http://dx.doi.org/10.1016/0261-5606(93)90016-5

Perée, E., \& Steinherr, A. (1989). Exchange rate uncertainty and foreign trade. European Economic Review, 33(6), 1241-1264. http://dx.doi.org/10.1016/0014-2921(89)90095-0

Sauer, C., \& Bohara, A. K. (2001). Exchange rate volatility and exports: Regional differences between developing and industrialized countries. Review of International Economics, 9(1), 133-152. http://dx.doi.org/10.1111/1467-9396.00269

Sercu, P., \& Vanhulle, C. (1992). Exchange rate volatility, international trade, and the value of exporting firms. Journal of Banking \& Finance, 16(1), 155-182. http://dx.doi.org/10.1016/0378-4266(92)90083-C

Thursby, J. G., \& Thursby, M. C. (1987). Bilateral trade flows, the linder hypothesis, and exchange risk. The Review of Economics and Statistics, 488-495. http://dx.doi.org/10.2307/1925537

Viaene, J., \& De Vries, C. G. (1992). International trade and exchange rate volatility. European Economic Review, 36(6), 1311-1321. http://dx.doi.org/10.1016/0014-2921(92)90035-U

\section{Notes}

Note 1. Unexpected changes.

Note 2. For more information, see: http://www.amar.org.ir/Default.aspx?tabid=133

Note 3. For more information, see: http://www.cbi.ir/default_en.aspx

Note 4. For more information, see: http://www.spac.ir/

Note 5. For more information, see: http://www.irica.gov.ir/

Note 6. The war between Iran and Iraq from 1980 to 1988 that is also known as the first Persian Gulf War.

Note 7. This is called labor productivity.

Note 8. Since this variable is calculated as a ratio there would be no linear relation between this measure and the export variable at left hand-side of the equation.

Note 9. For more information see: http://www.stata.com/stata12/

Note 10. Vertical lines in Figures 1-a and 2-a indicate the four periods.

Note 11. Coined in 1977, mainly reflecting a decline in the manufacturing sector as a result of an increase in the economic development of natural resources. 